\title{
Reflections on Open Spaces in a Residential Complex
}

\author{
Sepide Saiedlue ${ }^{1}$, Seyed Bagher Hosseini², \\ Seyed Abbas Yazdanfar ${ }^{3}$, Saeed Norouzian Maleki ${ }^{4}$ \\ ${ }^{1}$ Msc. Student, ${ }^{2}$ Associate professor, ${ }^{3}$ Assistant professor, ${ }^{4}$ Ph.D. In Architecture, \\ School of Architecture and Environmental Design, \\ Iran University of Science and Technology, Tehran, Iran \\ Sepideh_saieedlue@yahoo.com
}

\begin{abstract}
From the early 50 s onwards the major Iranian cities were subject to a massive immigration. The immediate solution to this crisis was to build a residential complex in the less populated areas. After few decades of accommodation, while having limited open space, this policy created physical, functional, semantic, environmental, and social problems. Today, the challenge confronted the designers and architectures are to improve the quality of both open spaces and living condition of the inhabitances while at the same time compete in the housing market with a limited budget for their expenditures.
\end{abstract}

Keywords: residential complex open space, open space factors, FANP

eISSN: 2398-4295 @ C 2016. The Authors. Published for AMER ABRA by e-International Publishing House, Ltd., UK.. This is an open access article under the CC BY-NC-ND license (http://creativecommons.org/licenses/by-ncnd/4.0/). Peer-review under responsibility of AMER (Association of Malaysian Environment-Behaviour Researchers), ABRA (Association of Behavioural Researchers on Asians) and cE-Bs (Centre for EnvironmentBehaviour Studies), Faculty of Architecture, Planning \& Surveying, UniversitiTeknologi MARA, Malaysia.

DOI: https://doi.org/10.21834/ajbes.v1i4.41 


\subsection{Introduction}

Change in the late twentieth century socio-demographic characteristics and cultural attitudes of urban policy brought diversity in the housing market. These changes had a profound impact on how to design and construct housing complexes (Einefar, 2001). It seems the new approach is to improve the quality of open spaces between the blocks in a residential complex or external environment since the desirability of improving these areas is directly related to the residential quality of living standards. Thus, it is believed that the validity of the ideas and designs for an open space does not only depend on the complex residential spaces but more importantly on how their housing quality is accountable to enhance the living standards.

Some experts have argued that open spaces in complex residential architecture have received less attention and that created practical problems for the inhabitances of a proper coordination and communication. The low quality of infrastructure components such as green spaces, water pool, an exercising and walking space, could result in structural disharmony. The physical factors (functional) surely have an impact, particularly on safety, relaxation and comfort along with abnormalities in individual behavior and social relations among residences. Ignoring the crucial role which a public open space in a residential complex usually plays, as well as semantic legibility and identity factors naturally create environmental and social dissatisfaction. Finally, concerning the importance of the public services in the structure of open spaces, in fact, could distort the smooth access to the transport system and other daily facilities.

Living in a small apartment with limited space in a residential complex located far from nature is stressful; therefore, in this regard, it is necessary to create public green spaces for individuals and families according to appropriate standards in a small housing condition. For residential complexes with small apartments and limited resources for the environmental quality, it is suitable to have a design review and conceptual reconstruction on architecture focus of attention. A new approach for designing small open spaces such as green yard or balconies and terraces inside the apartments has been a useful suggestion respectively. In recent years, there has been some attention among the designers and planners to improve their understanding of open spaces which consider open spaces as a place for exchange of ideas and learning social behavior, a place for better communication among the inhabitance of a residential complex, with the aims to increase the participation of citizens in a public open space and enhance the social and environmental security, and bring an understanding of how to live in a smaller community based on respect for diversity and differences.

\section{Literature Review}

\subsection{Urbanization, public open spaces, and private courtyard}


Urbanization is not limited to physical public space, but also concerns the private physical environment beyond the city. It creates social and cultural cooperation among citizen, it changes customs and traditions and also encompasses bond between citizens and public authority. Oswald Spingler argues that the city is a mental realm, a place where tradition and customs and attitudes of individuals and organizations come close to one another. The high-quality urban environment often satisfies the residential needs in which great numbers of the population have resided. In recent years, many discussions have raised in the urban environmental quality component issues. The most important of them, which also combine the satisfaction, are those factors that create a sense of belonging or identity, legibility factor that creates a sense of security and relaxation, sustains and renews the collective memory, factors that create a historical identity and a sense of belonging among citizens. The quality of the urban environment in intellectual and emotion as described by Michael Gülen in "The perfection and power" tell us how to regard the human psyche, the form, and its components and how they take place and shape (Mitchell Gülen, 2000). According to Lynch, citizens perceive urban environment only through an understanding of their visual perception of a quality which is created by themselves. The image and perception which people have about their environment are also the results of their feeling that is in its turn created by the environment where they live.

Factors concerning human environmental quality should give some comfort and attract the citizens of the area where they resided. To create a quality environment in the city urban planners need to re-conceptualize the economic, social, and cultural aspects, and policymakers, on the other hand, should improve their approach to urban environmental quality in their urban planning (Huang, 2006). Often, public space has constituted an important aspect of city planning and usually has a wider flexibility for changes in its shape to attract the people to continue their activities in their town (Paknejad, 2009). Public space is a common place for citizens located in common spaces which display the urban functional activities such as ritual ceremonies and celebrations (Madanipour, 2000). Social behavior in public space is the dominant social and cultural characteristics of the public space, hence, the study of behavioral patterns that determines and indicates how public spaces are used should influence the design and environmental planning in any given cities (Nozari, 2004). Moreover, residential open spaces are in fact crystallized the essence of the social life since these spaces, and social interactions provide an opportunity for the citizen to meet each others in these spaces (Waxman, 2004).

On the quality of the urban environment, Jane Jacobs in 1961 in his book "The Death and Life of Great American Cities" argues that the most important issues to resolve anomalies in this regards are the application of appropriate patterns of activity, the use of mixed methods, giving attention to the quality of the streets, permeability, and flexibility of open spaces. Lynch in his book "The Good City" (1981) also points out that improving the quality of urban life depends on the following seven factors: happiness, meaning, adaptability, access, control, and efficiency of justice. Benteli \& El (1990) in "Media Respondent" has been drawn ten criteria, which includes permeability, variability, legibility, 
flexibility, visual adaptation, wealth, belonging to colors, with regard to energy efficiency, cleanliness, and maintenance of ecosystems, as the norms that must be observed in an urban design.

The courtyard features are divided into three parts of physical, functional and semantic in a house. The physical part includes the geometry of the yard, combined space in the yard, privacy, closeness, hierarchy, and outlook. Moreover, climate, functional integration, naturalism, and social interaction are also other functions of a courtyard. Organization of open space in a variety of houses is oriented toward the courtyard shaped geometry. The design of closed spaces or the indoors is often drawn around it. The courtyard in a given house space is often designed for communication between people and nature or community as a whole (Haeri, 2009). The geometry of the courtyard usually has a regular order and is in the form of rectangular, which in the first stage of design gives feasibility for geometric rectangular in the courtyard and also are the pool and the garden also follow the same geometry.

\subsection{Definition of open space in residential complex}

The open Space area has been defined as a place without residences, personal ownership, and is managed by the joint management of the units (Mohamedzadeh, 2011). Open space in a residential complex includes side spaces in the open fields, pathways for pedestrians and vehicles, green space, communal spaces, parking and permanent and temporary stations, landscapes, furniture, and directional boards (Sun, \& Nashmira, 2005). This type of definition emphasizes on both the surrounded and not surrounded areas and describes open space without building form the constructed space is made up of one-twentieth of the total space while the entire public space is for recreational purposes or remains unused (Mohamedzadeh, 2011). Therefore, the main role of open space in a residential complex is to create an adjustment between the construction and human density, providing appropriate levels of the necessary framework which allows some activities (Mohamedzadeh, 2011). In fact, open spaces are designed to meet the needs of the residents, activities, and human communication, where its elements include access to routes for pedestrians and vehicles, to green space, two children's playgrounds, to places for sitting and rest temporarily (Nozari, 2004).

\subsection{Definition of open space in residential complex}

The open Space area has been defined as a place without residences, personal ownership, and is managed by the joint management of the units (Mohamedzadeh, 2011). Open space in a residential complex includes side spaces in the open fields, pathways for pedestrians and vehicles, green space, communal spaces, parking and permanent and temporary stations, landscapes, furniture, and directional boards (Sun, \& Nashmira, 2005). This type of definition emphasizes on both the surrounded and not surrounded areas and describes open space without building form the constructed space is made up of one-twentieth of the total space while the entire public space is for recreational purposes or remains unused 
(Mohamedzadeh, 2011). Therefore, the main role of open space in a residential complex is to create an adjustment between the construction and human density, providing appropriate levels of the necessary framework which allows some activities (Mohamedzadeh, 2011). In fact, open spaces are designed to meet the needs of the residents, activities, and human communication, where its elements include access to routes for pedestrians and vehicles, to green space, two children's playgrounds, to places for sitting and rest temporarily (Nozari, 2004).

\subsection{Methodology}

\subsection{Delphi Method and network analysis}

With extracts some components which affect the quality of open spaces in residential complex and due to a number of these components, hence the impossibility of measuring them the Delphi method which is a structured method shall be used. The group of decision makers, which consisted of six Ph.D. experts and four master degrees, experts in the architecture field and Urbanism planning, were selected. They have the tasks to specify the priority and importance of the factors which have been extracted and had to respond to them later. Then, the number of factors has been refined and thus allows us for the measurement of samples.

To obtain components which have the greatest impact on the quality of open space, residential complex the process network analysis based on the Saaty matrix method is used. The network analysis has flexible features, using simultaneous quantitative and qualitative criteria, and the ability to check the consistency of its judgments, and complex relationship (interdependencies and feedback) between and among the elements to be considered. Network analyzes consist of two parts, first control hierarchy, and second network relationship. The hierarchy controlling consists of relationships between objective, criteria and sub-criteria, and has an effect on the internal communication system, and includes the networking dependencies on elements and requesting subjects (Zebardast, 1999).

\subsection{Selecting residential complex sample for case study}

For this purpose, Ekbatan and Hormzan residential complexes have been selected. Ekbatan is one of the largest residential complexes in the Middle East and located in the west of Tehran, six districts in the fifth municipality. Its surface is 5904 square kilometers with 430981 inhabitants. Hormozan is also one of the largest complexes in the Tehran. Its geographical location is in phase 2 of the Shahrake Gharb and the district of the second municipality. It has 11 acres and 1269 residential units. To collect data according to the formula sample of Klein (3.2 times the number of items), randomly 96 residents of the residential complex (54 from Ekbatan and 42 from Hormozan) were selected. Sampling was 
in clusters, and the individuals were selected based on different social, age, and gender groups.
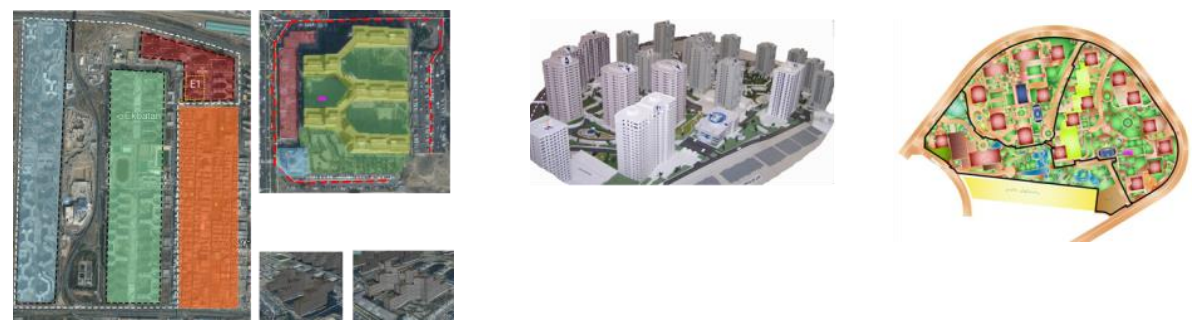

Figure 1:Ekbatan residential complex and Hormozan residential complex

\subsection{Results and Discussions}

To determine the characteristics of the quality of open space, we considered thirty-two subfactors concerning functional, physical, environmental, semantic and social factors. The degree of importance of each indicator was considered from one to five, and the experts have selected the factors of their priority and importance, and finally, some points were given to them. After collecting the factors, the experts selected and calculated their average based on 3.2 to a high degree of importance and became the basis of the classification of those sub-factors, and then on examining these sub-factors 21 finals of them for investigation were selected. From 21 final sub-factors, we selected six sub-factors for functional factor, three sub-factors for physical factor, six sub-factors for semantic factor, three sub-factors for an environmental factor, and finally three sub-factors for the social factor.

\subsection{Conclusion}

The purpose of this paper was to explain how to examine and improve the quality of open space in a given residential complex. Thus, after examining two residential complexes (Ekbatan and Hormozan) the findings were as follows:

The quality of a residential complex is a condition (and a term) which one may characterize or describe with two sets of five essential different but interrelated factors. The first set is a physical, one in which quality differs from what they have fundamentally been and also what improvement they were capable of generating came from its sub-factors such as materials, scales, and geometry. The second is an inclusive set which consists of four different factors that include functional, semantic, environmental, and social which in a traditional residential complex had originally been static or even stagnant -incapable of generating improvement from traditional design concept and practices - but over the course of time and for various historical reasons - urbanization, cultural improvement, climate 
change, and socialization - this set became subject to the impact of one or more modern architectural concept and designs. In fact, quality improvement becomes a fundamental characteristic of the residential complex when the interrelation between the physical factor and other factors (functional, semantic, environmental, and social) became crucial to an understanding of conceptual modernization. Ekbatan and Hormozan residential complexes, by their necessity to improve the quality in their open spaces, they became the subject of a case study for this research.

Improving the quality of the open spaces will bring crucial changes in the living standards of the residents in Ekbatan and Hormozan residential complexes. This improvement could eventually bring a new form of urban development while considering the quality of the residential complex based on physical, functional, semantic, environmental, and social factors. If referred to their responses to questionnaires which were distributed, the impact of this improvement shall help the most residents to become familiar with the new design and approaches, as well as create new comparative norms for open space in their residential complexes. This quality orientation for design deficiency can be satisfied with "Persian Garden" because in all responses to both case studies in these two residential complexes the lack of environmental factors could be observed. In this respect, the need for a new design and to improve the quality of open space, the following subfactors are Encouraged.

The interrelations between improving the quality of open space and residents' quality of life in residential complexes in the first step bring our design towards the search and recognition of some aspects of the quality factors which are partly the base of their requests because in this way a feasible reconstruction plan for designer will be crystallized. This first requires the improvement in physical factors and sub-factors which should be added to design and plan of development. However, that alone is not sufficient to bring quality improvement for residents if at the same time other factors are not taken into account. This will create a challenge to the designer and a question that how to improve the quality of both open space and living conditions and at the same time competing with the housing market with restrictions on the expenditure. A reasonable method to confront this challenge is to consider the second set of factors of a social capital along the financial and material investment. That means, in fact, to follow the construction market, while a variety of human materials and services are besides considered as the added value.

An appropriate design to improve the quality of life for residents in the residential complex should include the tastes and demands of the people by using all quality factors to be held accountable. For this reason, the semantic factor and its sub-factors such as vitality and legibility, not only make the faces of the complex realistically convenient, but also, improve the quality of life for residents in a smooth arrangement. By adding an environmental factor of design, in fact, the improvement in the quality of the open space will enter into a new stage of modern construction. That means a form of traditional architecture and a different design for open space with attention to the aesthetics of the building shall come together alongside the integration of human contacts with nature as a whole. Social 
factor and its sub-factors in the design provide cultural homogeneity and social security. Open space, admittedly, is a place for social relations while it is necessary that the security of the residents was considered as a priority in the design since it enhances the quality of life and living standards.

\section{References}

Bentley, et al., (1990), responsive environments, book designers (M Behzadfar, Translator). Tehran's University of Science and Technology Center.

Einefar, A.R.(2001). Analysis of the relationship between physical design and experience in residential neighborhood. Virtual: 1, Volume 1, Number 1 ; From page 28 to page 40.

Haeri Mazandaran, M., (1388), the House of Culture of nature, Tehran, Center for Urban and architecture research, printing.

Huang, .S. (2006) ." A study of outdoor interactional spaces in high-rise housing" Landscape and urban planning,vol.78,193-204,2006

Madanipoor, A, (1379)"the design of the urban environment, social and spatial vision process", translated by $\mathrm{F}$. Mortezai, Tehran, processing and urban planning, August 1379.

Mitchell, G. (2000). Indicators as tools to guide progress on the sustainable development pathway. Sustaining human settlement: A challenge for the new millennium, 55-104.

Mohammadzadeh, R. (2012). Assessment of Spatial and Physical Factors Quality of Sahand New Town Residential Communities Open (Outdoor) Spaces. Journal Fine Arts and Architecture magazine articles Tehran University Volume 3, Number 47, Fall 2012, page 29-38

Nozari, S, (1383), Open Space Residential Design Guidelines, page, year 14, No. 39.

Pakzad, Jahānšāh (2009), Syrandyshh in urban (III), Tehran: Shahidi

Waxman, lisa kinch 2004, more than coffee : an examination of people, place and community with implications for design . Ph.D. thesis, Florida state university

Zebardast. E (2011) The Application of Analytic Network Process (ANP) in Urban and Regional Planning. Journal Fine Arts and Architecture magazine articles Tehran University Article 7, Volume 2, Issue 41, Spring 2011, Page $79-90$ 